\title{
Atheism and the Apotheosis of Agency ${ }^{1}$
}

\author{
BENSON SALER AND CHARLES A. ZIEGLER
}

Brandeis University, U.S.A.

\begin{abstract}
This paper suggests that biological factors ought to be considered in attempting to explain distributions of theism and atheism across populations. In advancing our argument, we consider two recent efforts to explain atheism. The first, entered by William S. Bainbridge, is in the tradition of sociological theorizing. The second, proffered by Justin L Barrett, is an example of theorizing within the framework of the recently developed cognitive science of religion. While these two approaches are different in important respects, they both opt for environmental explanations of atheism. We give reasons for regarding purely environmental explanations as unsatisfactory both with regard to atheism and with regard to some (but not all) expressions of religiosity. We offer, moreover, a suggested modification of Barrett's approach that introduces a hypothesized heritable biological factor into his explanatory schema. By so doing, we enlarge his argument so that it accounts for more of what we know about atheism.
\end{abstract}

Keywords: theism, atheism, William S. Bainbridge, Justin L. Barrett, cognition, biological factors

We suggest that there are biological factors that relate to the distributions of theism, atheism, and an indifference to one or both. This is not to say that genes directly cause atheism, theism, or indifference. Rather, we argue that genetic variability in human populations may dispose analog differences in sensitivity or insensitivity to various features of behaviorally relevant environments, and that such differences tend to be reflected in attitudinal differences.

While we subscribe to the general paradigm that has emerged in recent years respecting the naturalism of theism as viewed within an explanatory

\footnotetext{
${ }^{1}$ The authors acknowledge with gratitude suggestions made by the Editor and by two anonymous reviewers for revisions of an earlier draft of this paper.
} 
framework derived from the contemporary cognitive, neural, and evolutionary sciences, we opine that that paradigm is deficient regarding the distribution of variations in human populations. Such populations are not genetically homogeneous. The import of that fact, and the possible significance of polygenic inheritance and polymorphisms, ought to be considered in a variety of studies dealing with the social and cultural dimensions of the human condition.

In parallel to other works that introduce biological factors into the understanding and explanation of variable religious and political attitudes (e.g., Alford et al. 2005; Bouchard \& McGue 2003; D'Onofrio et al. 1999; Eaves et al. 1990), we attempt something similar here. We suggest reasons for why, on the one hand, some people profess atheism or seem indifferent to theism in social environments marked by widespread theism, and why, on the other hand, in certain communities (such as the faculties of modern, secular universities) where there is widespread disinterest in, or overt rejection of, theistic claims, some persons are theists.

\section{Atheism and Theism}

Atheism and theism are like virtually all other high order concepts. That is, the more closely we examine their extensions, the more we recognize the complexity of the phenomena to which they are applied.

\section{Atheism}

We find that different persons conceptualize atheism somewhat differently. Some deem it the denial or rejection of the existence of a god or gods. Others compound that understanding by explicitly making belief central to it, for they define atheism as the absence of a belief in the existence of a god or gods. Still others, while not entirely rejecting the above conceptualizations, deem them too negative and, in effect, too parasitic on theistic ideology or religion. Rather than emphasize atheism in opposition to, and as a negation of, theism (as suggested by the derivations of those terms from classical Greek), some prefer to see it as 'essentially a form of naturalism', where 'its main evidential base is the evidence for naturalism' (Baggini 2003, 16). Atheism here is subsumed into a philosophical monism, a conscious and relatively sophisticated position that holds that all attempted explanations of the world should be of the same naturalistic cast, and that we should avoid philosophical dualism whereby many things are explained naturalistically and certain other things are accounted for supernaturalistically. 
The above conceptualizations by no means exhaust the many subtleties, parsings, hedges, and advocacies encountered in a sizeable literature on atheism found in libraries and websites. To complicate matters further, there are debates about where to draw boundaries between atheism and agnosticism; differential characterizations of agnosticism (e.g., some people are likely to claim that they don't know or that they have no opinions about the existence of a god or gods, whereas others may add that they lack empirical evidence or conclusive logical arguments on the subject); contrasts between those for whom, as William James $(1929,8)$ puts it, religion is 'an acute fever' and those for whom it is 'a dull habit'; differences between militant atheists and those for whom 'atheist' is, as it were, a residual category to which they pertain largely because of indifference to theism and its proponents; and much else. In brief, there is considerable complexity (and a treasure-trove of subtleties) involved in variegated attempts to characterize atheism. In many popular usages, nevertheless, atheism implicitly or explicitly implies or presupposes theism as a contrastive concept.

\section{Theism}

Central to our understanding of theism is the postulation of the existence of a god or gods. But there is usually more to theism than that. One important matter, of course, is to determine what people may understand or mean by god. Sometimes that term or a corresponding term in another language is used quite broadly. Among the classical Greeks, for instance, as Ulrich von Wilamowitz-Möllendorff (1956 [1931]) points out, the term theós (from which we derive our terms theism and theology) was often and widely used as a predicate term, which raises the interesting question of what constraints the Greeks may have recognized (at different times and perhaps in different places) with respect to saying that something 'is' a god, even in metaphorical extensions. When Euripides wrote (Helen, 560) 'For to recognize friends is also a god', his poetic formulation was certainly meaningful and probably pleasing to his Greek audiences (and, we would like to think, meaningful and pleasing to us as well), but what predications might have been unmeaningful or displeasing, and why? Some of the Greek Neoplatonists, to cite another example, used theós to refer to a galaxy of postulated spiritual entities, often including postulated human souls. And, as we shall soon point out in more detail, the psychologist Justin L. Barrett includes a variety of conceptualized beings under the rubric 'god', and we follow him in doing so in this essay.

A related problem has to do with the postulated relationships of gods to human beings. Gods whose postulated attributes include capacities and 
dispositions for making significant differences in human life tend to be deemed by many scholars and others as the most characteristic or 'most prototypical' exemplars of the category god. Such gods are often credited with access to what Boyer $(2001,152)$ calls 'strategic information', that is, 'the subset of all the information currently available (to a particular agent, about a particular situation) that activates the mental systems that regulate social interaction' (emphasis in original). Gods who can access strategic information are usually depicted as knowing a great deal (or perhaps even everything) about the humans with whom they may choose to engage in a social relationship. But there are other conceptualized entities, glossed as gods, that lack access to strategic information and that have little or no interest in interacting with humans. Aristotle's Unmoved Mover is an extreme example. That entity, though referred to as theós, and credited with being immaterial, eternal, and immutable, is actually an intellectual principle in a theory of causality, and one that serves Aristotle as a device for ending the intellectual chaos of infinite regress. The Unmoved Mover takes no notice of human beings. It is, as someone once said, mind minding itself. It thinks only of its own perfection, for to think of anything else - all other things being less perfect - would be to subvert or compromise its perfection. Such an entity is probably better thought of as pertaining to the category 'theistic metaphysics' than to the category 'religion', though it is conceivable that some persons may choose to 'worship' or celebrate it (or some other abstract principle) as a way of affirming order in the universe.

Our brief discussion above indicates that there is a good deal of variety in what may be included under the rubrics 'theism' and 'god'. That is also the case for 'religion'. While you can have theism without religion, and, according to some, religion without theism, theism is usually central to religion, and what we conventionally recognize as religion usually pivots on theism. We think that the categories to which the terms god, theism, and religion pertain - as well as many other descriptive and analytical categories - are best conceptualized in terms of central tendencies and peripheral extensions rather than in terms of essences and boundaries. There are instantiations of each category that people are likely to regard as more central to the category, and thus better or clearer exemplars, than others. Intellectually, the approach to the categories god, theism, and religion that we prefer rests on combining the idea of family resemblances with certain insights and stratagems derived from prototype theory in the cognitive sciences (for a succinct exposition of what is involved, see Saler \& Ziegler 2005, 218-220; for a more extensive treatment, see Saler 2000 [1993]). 
We support the view that theism, as we conceive it, is naturally generated. And we acknowledge that, as many scholars affirm, much that we tend to regard as religion turns on theism, and so, at least to that extent, religion, too, is naturally generated. But to extend this discussion further with respect to 'theology', another derivative of theós, would involve us in complexities that are tangential to the purpose of this paper. Suffice it to say that it is our impression that the term theology is used in wide and narrow senses. In its wider extensions, it tends to overlap with much that we associate with theism, albeit usually offering or implying a reflective overview of what it spans. In its narrower extensions, theology refers to the conscious, deliberate, systematic efforts of (often credentialed) individuals to make sense of particular traditions of theism. We prefer to term theology in this narrow sense 'formal theology'. In a valuable paper dealing with the philosophy and psychology of religious belief, Ilkka Pyysiäinen $(2003,122)$ argues that engaging in what he calls theology (and what we call formal theology) 'entails that one adopts a representational theory of mind and regards religious beliefs as something to be reflected upon'. And ' $[\mathrm{t}]$ he existence of religious beliefs', he maintains, 'is explained by a panoply of mental mechanisms' $(2003,110)$, a thesis that we explore in part later.

\section{Two Recent Approaches to Atheism}

Two recent efforts to account for atheism command our attention. One is a paper published by the sociologist William S. Bainbridge (2005) in an electronic journal. The other is a chapter in a book written by the psychologist Justin L. Barrett (2004).

Bainbridge and Barrett differ significantly respecting the specific situational factors to which they attribute major causality. More broadly, moreover, they appear to differ in their perspectives on the architecture of the human mind (Bainbridge seems to favor a general purpose or ' $\mathrm{CPU}$ ' view of the mind whereas Barrett gravitates to the contemporary modular theory). And they diverge regarding the larger theoretical framing of their arguments. While one might, perhaps, relate Bainbridge's thesis to an evolutionary background, Bainbridge himself does not attempt to do so. Barrett's overview, however, has an explicit evolutionary component, even if his particular explanation of atheism is only indirectly connected to an evolutionary perspective.

Despite important differences in their approaches and explanations, Bainbridge and Barrett are nevertheless alike in certain crucial respects. 
They both attempt to account for atheism solely by invoking environmental factors. Their overall argumentative strategies, moreover, are very similar. They begin by presenting a theory of religion that emphasizes some factor - a different factor in each case - that promotes theism. Then they proceed to suggest how and why some individuals may be less influenced by that factor than their fellows, and so more vulnerable to atheism.

Bainbridge, whose approach is outside of a self-conscious evolutionary context, theorizes in a way that is (still) mainstream in the social sciences (see Tooby \& Cosmides 1992 for some cogent criticisms of what they call 'The Standard Social Science Model'). We judge the particulars of his argument, however, to be novel and interesting. Referring to a 'compensator' theory of religion that he played an important role in developing, Bainbridge suggests that a lack of, or a diminishment of, social obligations encourages disbelief in a god or gods.

Barrett, though ultimately grounded in an evolutionary perspective, takes an environmental jog to explain atheism. That is, Barrett sees theism as a byproduct of evolutionary adaptations and therefore as natural to the human condition, whereas he deems atheism to be an anomaly that needs to be explained by the operation of environmental factors in specific communities.

We summarize below Bainbridge's and Barrett's approaches. Here, however, we want to orient the reader to our own position. Whatever else we might say about them, we think that both Bainbridge's and Barrett's accounts of atheism are deficient because, in advancing their respective environmental explanations, they both in effect treat human populations as if those populations were biologically homogeneous. We think that that is a mistake, both as a default position and as the foundation for an explanation of atheism.

\section{William S. Bainbridge}

Bainbridge begins his essay by declaring that historical studies and partisan debates notwithstanding: 'We know surprisingly little about Atheism from a social-scientific perspective' $(2005,1)$. Such is the case because 'systematic attempts to understand Atheism as a social or psychological phenomenon, employing rigorous theory and quantitative research methods, have been rare' $(2005,1)$. He acknowledges that there are some investigations that deserve our attention, and he specifically cites studies by Bernadette Hayes (2000) and by Wolfgang Jagodzinski and Andrew Greeley (n.d.). Bainbridge characterizes the former effort, however, as 'resolutely atheoretical' (2005, 
1), and he judges the latter to be theoretically inadequate for sorting out variables and for justifying its authors' 'interesting assumption that Atheists experience no need for religion' $(2005,2)$.

'Probably', Bainbridge writes, 'Atheism has many causes, although one might guess, as with many other social phenomena, that a relatively small number of them are really significant for substantial numbers of people' $(2005,2)$. His strategy is to invoke a recently amended version of 'the compensator theory of religion' (Bainbridge 1995; Bainbridge \& Stark 1979; Stark \& Bainbridge 1979; 1980; 1985; 1987), and to use that theory to generate hypotheses and to make sense of data both from a four-language, web-based questionnaire and from supplemental data found in The General Social Survey.

The theory of religious compensators is grounded in a host of assumptions about the human condition. Like other animals existing in a world of rich resources but numerous hazards, Bainbridge observes, we humans seek rewards while attempting to avoid or minimize costs. We are better able to do so than other animals, he affirms, because of superior information-processing abilities. Thanks to our powerful brains, he states, we have high order capacities for language, for analysis, and for planning, and our minds direct 'action by developing explanations - statements about how and why rewards may be obtained and costs are incurred' (2005, 2, emphasis in original).

Stark and Bainbridge (1987, 35-37, summarized in Bainbridge 2005, 3) hold that in the absence of a desired 'reward' (something that will satisfy human needs), people will often accept the postulation of reward attainment in the distant future or in some context that cannot immediately be verified. Given that understanding, they use the term 'compensator' for the postulation of some reward 'according to explanations that are not readily susceptible to unambiguous evaluation'. Some compensators substitute for single, specific rewards, others for clusters of rewards that may be of considerable scope and value. While humans prefer verifiable, immediate rewards to compensators, and while they may attempt to exchange the latter for the former, they often live with compensators in lieu of attained rewards. Stark and Bainbridge (1987, 39, cited in Bainbridge 2005, 3) go on to suggest that: 'The most general compensators can only be supported by supernatural explanations.' In consonance with that view, they maintain that 'Religion refers to systems of general compensators based on supernatural assumptions' (Stark \& Bainbridge 1987, 39, cited in Bainbridge 2005, 3, emphasis in original). 
Conceiving of religion as a system of general compensators allows for a complex logic of atheism and of human religiosity. Thus, for instance, Bainbridge writes, if a person could have all the rewards that he or she might desire, that person would have no need of compensators 'and therefore could be an Atheist' $(2005,3)$. But all of us face death, and so at some level we are all objectively deprived, and we are thus rendered open to general compensators $(2005,4)$.

The compensator theory of religion, Bainbridge notes, is a social theory as well as a psychological theory $(2005,4)$. In explicating the theory's social dimension, Bainbridge finds it useful to amend the theory by distinguishing between primary compensation and secondary compensation. The first refers to people substituting a compensator for a reward that they desire for themselves. The second refers to the substitution of a compensator for a reward that someone is obliged to provide to another person $(2005,4)$. By way of an anecdotal illustration of secondary compensation, Bainbridge recalls how his nurturing great-grandmother sang hymns to her brother during several weeks when her sibling lay dying of typhoid. The hymns and their promises constituted something of a compensation for effective material medical help (an immediate, verifiable 'reward') that the caretaker could not provide $(2005,5)$.

Bainbridge notes that the literature dealing with compensators and religion has concentrated on primary compensation $(2005,5)$. He remarks that secondary compensation also deserves our attention in that it may be 'a major factor in the creation and maintenance of religious organizations', for '[i]f religious compensators do not actually satisfy sufferers' needs very well, these compensators might still satisfy the sufferers' exchange partners' obligations to provide assistance' $(2005,5)$.

Most of the remainder of Bainbridge's essay is given over to supporting the hypothesis 'that an important source of Atheism is lack or weakness of social obligations and thus reduced need for secondary compensation' (2005, 22). Drawing largely on data from a web-based questionnaire, Bainbridge finds support for various predictions derived from his compensation theory of religion (e.g., that atheists are more common among single persons than among married persons, that atheists will have fewer serious familial obligations to other people than religious persons, that atheism will be more prevalent among people who cohabit without being married than among married cohabiters, and so forth). Bainbridge also briefly discusses 'secularization', and he relates it to decreasing fertility in contemporary European nations and the increasing roles of governments or public agencies in those 
countries as social providers, thus presumably decreasing need among individual citizens for the provision of secondary compensations.

While Bainbridge's brief remarks about decreasing fertility may suggest some biological considerations, Bainbridge treats fertility as a situational factor and not a biological variable. His one, fleeting reference to biological variables occurs on page five, where he declares that ' $[t]$ raditionally, and perhaps rooted in humans' biological natures, females are more nurturant and more concerned with intimate social relations than men are', and that females 'have a more direct obligation for caregiving within the family' than men, and that because this is (allegedly) so, females 'might have more occasion to resort to secondary compensation when they cannot materially provide the help or other rewards they are obligated to give'.

It is important to note that Bainbridge does not claim to prove his hypotheses. He explicitly acknowledges that his dataset 'is better suited for exploration than for definitive theory testing' $(2005,11)$, since the web-based survey on which he draws has a non-random sample of respondents. His goal, Bainbridge tells us, is 'to illustrate and refine a specific theory' (2005, 8).

In our evaluation of Bainbridge's approach, we find certain aspects of it to be problematical quite independently of its failure to consider the possible significance of biological variables. Most especially, there is the crucial linkage between Bainbridge's compensator theory of religion and atheism, a linkage, we have already noted, that turns on the distinction between primary and secondary compensation.

'Primary compensation', Bainbridge tells us, 'is psychological, satisfying the emotional need of the believer' $(2005,4)$. We surmise from this that in primary compensation the individual must in some sense believe the explanation involved in the compensation to obtain need-satisfaction. That would also seem to be the case in secondary compensation for individuals who are the receivers of the compensation offered. But it does not follow that the providers of secondary compensations must be believers. The act of giving, as we understand it, primarily satisfies a social need of the giver, namely, the need to preserve vital (often familial) relationships. The postulated linkage between secondary compensation and atheism, we think, is logically compromised by the fact that it is unnecessary for obligated providers to be believers. It is only necessary for the compensations that they proffer to be accepted or believed by the receivers. We must allow for the very real possibility that atheists may make excellent providers. 


\section{Justin L. Barrett}

The last two decades have witnessed the development of an imaginative and powerful approach to understanding religion, an approach nurtured by the cognitive, neural, and evolutionary sciences. Scholars working within that paradigm tend to fall into one of two broadly construed camps when they theorize about the origins of religion. Some - the 'adaptationists' - suppose that affect-laden ideas and constructs central to religion were selected for because they conferred adaptive benefits on those small groups of Pleistocene hunters and gatherers who elaborated and transmitted them. Most particularly, it is hypothesized, shared commitments of a supernaturalistic cast promoted social solidarity within small bands, thus conferring competitive advantages over human groups that were less ideationally and affectively organized or integrated (see, for example, Wilson 2002). In contrast, numbers of other scholars - we might call them 'derivationists' - do not think that religion originated as an adaptation, no matter how functionally important it may have eventually become. They hold that the ideational and organizational elements that we deem central to religion not only did not evolve together (Atran 2002), but that various of those elements were originally non-adaptive byproducts of the evolution of capacities and dispositions that did offer adaptive advantages. In this view, religion derives from, and is 'parasitic' on (Boyer 2001; 2004), evolved propensities that play important roles in human life quite apart from religion and that presumably would be in evidence even if there were no religions. Justin Barrett is a major contributor to this latter view.

Belief in gods, Barrett $(2004,21)$ writes, 'arises because of the natural functioning of completely normal mental tools working in common natural and social contexts'. He employs the term 'god' broadly, including within its purview a variety of 'superhuman beings' (such as 'ghosts', 'demons', 'chimeras', the 'supreme gods' of various traditional religions and, perhaps in some modern cases, 'space aliens'), so long as 'a single group of people' believes in their existence and that belief affects behavior $(2004,21)$. Such 'gods', Pascal Boyer (1994; 2001) argues, largely conform to our intuitive ontological assumptions and expectations respecting 'persons' and, more broadly, living things. Such conformance makes them plausible and facilitates learning about them. But they also typically depart from those assumptions and expectations in a small number of counterintuitive ways, and that tends to render them attention-getting and memorable. Accepting Boyer's characterizations, Barrett refines our psychological vocabulary by terming gods 'minimally counterintuitive' concepts $(2004,22)$.

Human ideas about gods, in Barrett's psychology, arise in naturalistic and almost inevitable ways. We cannot rehearse here the intricacies of his 
argument. Suffice it to point out that Barrett's cognitive approach to religion has as its mainspring the processes whereby beliefs are created. Those processes are governed by the human mind, conceived of as an information processing system of considerable complexity.

Barrett calls some of the mind's subsystems 'tools' or 'devices', in keeping with his metaphorical description of the mind as a 'workshop'. They operate automatically at an unconscious level and are dedicated to solving specific problems on the basis of information that stems chiefly from non-verbal experiences. Barrett's uses of the words 'tool' and 'device' correspond to the ways that numbers of other cognitive scientists employ the more technical terms 'module' and 'mental module'. Mental modules are conceptualized as evolved, species-wide, domain-specific, information processing structures that have both inputs and outputs. Inputs may stem not only from perceptual apparatuses but also from the outputs of other modules. This is important, for there is often synergy among modules, and the ever-developing ecology of the mind is shaped in significant ways by feedback and functional cooperation.

Barrett deems certain 'tools' to be of crucial significance for the formation and functioning of non-reflective beliefs, beliefs that guide many of our daily activities without our necessary awareness of them. Much of what many cognitive scientists regard as 'intuitive knowledge' and 'intuitive expectations' rests on non-reflective beliefs. We expect rocks to fall to earth if we throw them into the air; we take it for granted that normal human beings cannot walk through solid walls; and so forth. Non-reflective beliefs may sometimes blaze into consciousness as intuitions when prompted by situations requiring individuals to create or evaluate reflective beliefs. The latter are beliefs that are consciously held and are susceptible to conscious reflection. Examples include the articulated, ratiocinated, and learned doctrines that scholars commonly associate with formal theology. Reflective thinking, indeed, would also appear to be of significance in conscious inclinations towards, or thoughtful commitments to, atheism (Pyysiäinen 2003; 2004).

The conscious belief structures of individuals, Barrett holds, depend for their continuance on interactions with our intuitions. Those intuitions, the bringing into consciousness of non-reflective beliefs, serve as default options for reflective beliefs, they enhance the plausibility of reflective beliefs that harmonize with them, and they help shape the memories that people may draw on in forming new reflective beliefs. ${ }^{2}$

\footnotetext{
${ }^{2}$ Barrett (2004, 17, n.1) notes that Sperber (1997) makes a distinction similar to his non-reflective/ reflective contrast; Sperber employs the expressions 'intuitive beliefs' and 'reflective beliefs'. In fact, numbers of scholars, utilizing somewhat different vocabularies, affirm the importance of similar distinctions. See Pyysiäinen 2004 for both an inventory of such distinctions and an analysis and overview of what they suggest about human thought, especially with respect to religious concepts.
} 
One of the 'tools' operant in infancy and for the rest of normal human life is what Barrett calls a 'hypersensitive agency detection device' (HADD). Agents are conceptualized as living entities that instigate goal-directed actions based on their own mental states, mental states that include desires and purpose relevant to need-satisfaction. Agency detection is of great importance in human life, not only in dealing with conspecifics but in avoiding predators, tracking prey, and in still more ways (as suggested by the current cognitive theory of religion to which Barrett has contributed). Numbers of cognitive scientists (e.g., Atran 2002; Boyer 2001) maintain that our agency detection module is extremely sensitive. That is, its threshold is relatively low for detecting agents. Indeed, it may often falsely indicate that an agent is present. False positives, however, are not only tolerable but of survival value, for, as Stewart Guthrie (1993) points out in adapting Pascal's Wager, if we mistake a rock formation for a hungry bear, little is likely to be lost, whereas if we mistake a hungry bear for a rock formation, we may lose much.

One consequence of hypersensitivity is that the agency detection module responds to what it identifies as physical traces of agency even in the absence of a causal agent. As Barrett $(2004,34)$ notes, '[w]e don't always see important agents in our environment, only the consequences of their behavior'. This tendency to respond to what we may deem the slightest hints of agency in the environment is at the root of beliefs in gods. Barrett, to be sure, maintains that a number of the mind's structures or sub-systems are involved in forming beliefs. But among those structures, in his view, the agency detection 'device' is of special significance in producing beliefs in god-like beings.

The cognitive processes that connect the agency detection module to belief in god-like beings produce what may be termed 'the apotheosis of agency', whereby postulated agents are elevated to the 'godly'. Although Barrett devotes several chapters to these processes, we can only sketch them here, omitting his many examples and his discussions of empirical studies that support his claims.

Barrett and numbers of others suppose that the agency detection module has been selected for in evolution. It detects agent-like living organisms embedded in an environment that includes non-living entities. The module discriminates between these two macro-classes by invoking intuitive knowledge of a certain few of the characteristics of, respectively, agent-like living organisms and non-living phenomena. When the module confronts perceptual inputs from some entity that does not fully conform to intuitive assumptions about non-living objects, and that exhibits certain characteris- 
tics of agent-like living organisms, it registers agency. This triggers another mental 'tool', or set of interactive mechanisms, termed the 'Theory of Mind', or 'ToM', that automatically attributes agent-like mental properties (such as desires and intentions) to the detected entity.

While in many cases the scanning of perceptual inputs unequivocally identifies an entity as a living organism or a non-living object, sometimes the perceptual input is ambiguous. When this occurs, as noted above, the mind tends to assume an agent, which, in effect, may well be the safest option open to it. Indeed, as Barrett and others maintain, the agent detection module has been disposed by evolution to register agency and to leave the task of gathering confirming or disconfirming information to other mental tools. If the gathered information is disconfirming, the intuition of agency is quickly abandoned. If the gathered information remains ambiguous, however, the intuition of agency is retained. In many such cases the entity involved is, in actuality, an object (as distinct from the presumed trace effect of some object). But it has become an object to which mental properties have been attached by the ToM, thus creating the non-reflective belief (which by default can become a reflective belief) that it is an agent endowed with needs and goals of its own.

According to Barrett $(2004,33)$, this 'tendency to attach agency to objects contributes to the formation of religious concepts'. He describes various ways this can happen, of which the following three are representative: (1) by detecting agency in an object that is misperceived as human-like but that displays non-human capabilities - thereby encouraging belief in supernatural agents (e.g., a whispy, wind-blown fragment of fog momentarily assumes a configuration that is misperceived as a disembodied human face, thus fostering belief in the existence of ghosts of dead humans); (2) by detecting the presence of agency in the seemingly purposeful movements of entities that are held to be objects (i.e., entities not normally attributed will, purpose, and intelligence) - thereby reinforcing belief in the existence and manipulative powers of a known god-like being (e.g., a tree branch breaks and destroys the house of a known blasphemer, thus confirming the villagers' belief in their vengeful tree-god); and (3) by detecting the presence of agency from agent-like traces that seemingly do not match those produced by any known natural or supernatural agent - thereby prompting belief in the existence of hitherto unknown god-like beings (e.g., contemporary so-called 'crop circles' are believed by some to be traces of beings from outer space who possess god-like powers, and that belief contributes to the creation of a new god-concept and certain religions based upon that concept). 
It is apparent from the preceding discussion that the sensitivity of the agency detection module is the critical element in initiating the apotheosis of agency and the consequent bias toward theism. For, as Barrett $(2004,90)$ maintains, the module's tendency toward over-detection 'prompts us to find agency among the ambiguous information around us. Such tendency warmly receives the idea of gods and makes belief in gods very natural.'

Barrett, in consonance with likeminded others (Boyer entitled his 1994 book The Naturalness of Religious Ideas), stresses the naturalness of theism. That position (which the authors of the present paper endorse) may seem to produce a conundrum. If, as Barrett, Boyer, and others believe, theism is natural, what about atheism? Is its existence somehow unnatural? How, indeed, do atheists free themselves from the shackles of panhuman cognitive processes, processes that involve powerful mental tools that function below the conscious level and that often promote or support ideas about gods? 'The answer', Barrett $(2004,113)$ declares, 'is to change the environment in which the mental tools operate'.

In Barrett's view, the crucial link between his account of a broadly defined theism (which he sees as central to religion) and the existence of atheism is a special environment that makes atheism more likely than would be the case in other environments. In this special environment a cluster of conditions prevail, most of which either thwart or reduce theistic-consistent outputs from the agency detection module.

The first of these conditions is that the environment must offer a nontheistic candidate for belief that can 'satisfy' theistic promptings from the agency detection module. For, according to Barrett $(2004,110)$, '[i]f we tell [the module] that it has misexplained something, it demands that we come up with a satisfactory counterexplanation'. The most salient counterexplanation stems from evolutionary theory, and Barrett $(2004,113)$ notes that for some individuals 'natural selection amounts to a sanitized and scientifically sanctioned "god" that may displace God".

The next two conditions reduce the frequency of the module's theistic outputs. Barrett $(2004,33)$ avers that situations that threaten survival heighten the module's sensitivity. The frequency of theistic outputs, he maintains, will be high if the only occupations available are those that often create anxiety related to the survival of self and family. It will also be high if individuals are surrounded by non-human organisms that persistently trigger ambiguous detections of agency that result in theistic outputs. Hence, the second condition is that the environment must provide lucrative employment in occupations that do not create anxiety related to survival. And the third 
condition is that the environment must be one in which the individual is surrounded chiefly by agents that are obviously human - a condition satisfied by urban environments.

Barrett also posits two supplemental conditions. First, the environment must be pluralistic, so that stories about the religious experience of any one person will ordinarily carry little immediate relevance for others. Second, it must be an environment that provides opportunity for reflection within a non-theistic community whose members are also engaged in reflective thought. The latter condition allows individuals time to form reflective beliefs that override non-reflective theistic beliefs.

In brief, Barrett claims that a tendency toward atheism will exist to an unusual extent in human groups exposed to pluralistic, urban environments where natural selection is widely accepted as the agency responsible for the myriad forms of life known, where there are rewarding opportunities for employment in occupations that do not create anxiety related to survival, and where there is ample opportunity for reflective thought within a community of non-theistic others who are also given to reflective thought. Such environments, Barrett notes, are relatively uncommon. They are to be found chiefly in developed countries where, for the most part, they are available to privileged elites.

Barrett also points to academics as saliently constituting groups that are exposed to such environments in contemporary society. The connection between his special environment, academics, and atheism, moreover, appears to receive objective support from surveys which show that the percentage of atheists among academics in the United States is far greater than that among the U.S. population at large. ${ }^{3}$

Barrett's approach leads him to conclude that atheism is indeed somewhat unnatural. He asserts that atheism, historically considered, has always been a minority position when compared to theism. He attempts to account for this by claiming that theism is able to prosper in almost all environments

\footnotetext{
${ }^{3}$ In 1914 psychologist James Leuba surveyed individuals randomly selected from a standard reference work, American Men of Science. About two-thirds of the physicists, biologists, astronomers, mathematicians, and others surveyed were professors at institutions of higher learning, and $58 \%$ of them expressed disbelief in, or doubt about, the existence of God. Leuba also conducted surveys of historians, psychologist, and sociologists, most of whom were academicians, and he reported similar or higher percentages (Leuba 1916). In 1996 two investigators replicated Leuba's survey of U.S. scientists (Larson \& Witham 1997; 1998). They found that the percentage of disbelievers and doubters was $61 \%$, indicating no great change since 1914 . To the extent that these percentages are representative of the proportion of atheists among U.S. academics generally, they are much larger than among the general public in the United States. According to Gallup and Lindsay $(1999,99)$, about five percent of the U.S. population was atheistic in the closing years of the twentieth century.
} 
for the reasons that he gives whereas 'atheism requires a narrow band of environmental conditions in order to thrive' $(2004,122)$.

It may be recalled that Bainbridge attributes an important source of atheism to weak or absent 'intimate' obligations in human social relationships. In contrast, Barrett finds that source in a cluster of special environmental conditions that constrain or channel agent detection. Both perspectives, nevertheless, may be termed 'environmental' in the sense that a heightened vulnerability to atheism is viewed as resulting from conditions external to the individual.

\section{Towards a More Complete Explanation}

In describing the approaches of Bainbridge and Barrett, we have noted that the former is framed in accord with the Standard Social Science Model. Not surprisingly, Bainbridge avails himself of the concept of mind that informs that model. He declares that the mind is 'a complex but finite information processing system that functions to identify problems and attempt solutions to them' (Bainbridge 2005, 2). That statement and others suggest that for Bainbridge the mind is a sort of general-purpose computer, but one in which the programs that guide its functioning are not innate. They are obtained, rather, from the culture in which the individual participates. This domain general concept of mind differs from the idea of mind entertained by Barrett.

Barrett's explanation of atheism rests upon a modular concept of the mind in which the modules are domain specific. The development of these modules, moreover, although stimulated by environmental triggers, is nevertheless largely independent of the ambient culture. Each module has certain panhuman characteristics that have been naturally selected for solving problems in its special domain.

The modular theory of mind, though controversial, is supported by a number of studies in diverse fields, including psycholinguistics, comparative psychology, and neurobiology. It probably commands the endorsement of most contemporary cognitive scientists. ${ }^{4}$ In any case, it is strongly linked to the sciences. Because of that linkage, explanations that crucially incorporate it (such as Barrett's) would seem to be more amenable to modification (and possible refutation) in consequence of scientific advances than is the

\footnotetext{
${ }^{4}$ The philosopher David Buller, who is among the harshest critics of modularity, nevertheless affirms that the traditional concept of a domain general mind 'is the view that most (but not all) cognitive scientists [...] now reject in favor of a view of the mind consisting of a number of psychological modules' (Buller 2005, 54).
} 
case for explanations that crucially depend on the Standard Social Science Model's domain general concept of the mind. Inasmuch as suggesting such a modification is the primary purpose of this paper, our analysis in what follows will focus on Barrett's explanation of atheism.

Like all such explanations, Barrett's is not designed to explain why this or that individual is an atheist. Rather, it seeks to explain atheistic trends in groups. ${ }^{5}$ In effect, and despite the absence of impressive (or intimidating) number crunching, it amounts to a statistical argument that attempts to explain why the fraction of atheists is likely to be anomalously high in groups exposed to the influence of a cluster of special environmental conditions. This influence is probabilistic, not determinative. Indeed, data that we have reviewed indicate that a fraction of theists remains in such groups despite the prevalence of the special conditions. Since Barrett's special environment explanation focuses on atheists, the implicit default explanation for group members who are theists becomes, in effect, the 'catch-all' factor of a causal chain of chance events in the idiosyncratic life-histories of these individuals. Smuggled into Barrett's explanation, in our reading of his book, is the assumption that individuals are essentially homogeneous regarding the innate sensitivity of their agency detection modules and their innate susceptibility to the influence of the special environmental conditions, but that chance events in their life histories involving interactions with other facets of the environment render some individuals less susceptible than some of their fellows. In this context, 'susceptibility' refers to the extent to which the operation of an individual's agency detection module is liable to be constrained or muted, resulting in a vulnerability to atheism and a trend toward atheism in the group. The muting or limiting of the module in Barrett's schema, and the resulting fractions, respectively, of theists and atheists, are determined solely by environmental factors.

Barrett does not address the possibility that a biological factor may be involved in whether a person is a theist, atheist, or (harder to deal with) is basically indifferent to theistic and atheistic blandishments. We shall soon point to evidence that suggests such a factor. By including that factor in our overall understanding, we modify Barrett's approach, and by so doing

\footnotetext{
${ }^{5}$ Anthropologist Pascal Boyer argues that, if one's purpose is theory-building, the question of why a particular person is an atheist is not of crucial importance. For although we may suppose that some specific causal chain of life-events led a particular person to become a disbeliever, Boyer $(2001,319)$ holds that 'it is in principle futile to try to identify that causal chain'. A theoretical explanation of atheism, Boyer continues, can only attempt to account for 'trends in groups'.
} 
enlarge his argument so that it can account for more of what we know about atheism. We consider the sensitivity of the agency detection module entailed in Barrett's approach to be an especially suitable candidate for modification because, as previously pointed out, it is the module's sensitivity that is crucially responsible for initiating the apotheosis of agency from which a theistic bias results. Hence, any factor that reduces the module's innate sensitivity (or that produces an effect equivalent to such reduction) will increase the individual's vulnerability to atheism.

As noted earlier, Barrett is not alone in claiming that the hypersensitivity of the agent detection module plays a central role in creating belief in god-like beings, ${ }^{6}$ and that it does so by means of a cognitive process that amounts to the apotheosis of agency. To summarize and reiterate in slightly different language an important point entered above, Barrett holds that a cluster of special environmental conditions mute the output of the module, thus lessening the probability that the apotheosis will occur. Effectively, this is equivalent to reducing the module's sensitivity, which differentially heightens vulnerability to atheism, depending on the individual's life history. We propose to modify this schema by hypothesizing that the module has an innate sensitivity that varies across individuals because of a 'heritable' biological factor (i.e., one stemming from genetic variation).

In our view, while the members of a group exposed to Barrett's special conditions may indeed experience, in effect, a diminution of the module's sensitivity, such reduction will be superimposed upon the module's innate sensitivity, an innate sensitivity that, because of our proposed heritable biological factor, will tend to vary from person to person. Hence the cause of variation in resultant vulnerability to atheism across group members will have environmental and biological dimensions. This, of course, will also be true of individuals in a group exposed to an environment that lacks the cluster of special conditions. In that case, however, the influence of the environment will not generally tend to promote movement toward atheism within the group.

To enhance the plausibility of our hypothesis, two questions must be addressed. First, is there a genetic mechanism that could cause variation in the sensitivity of the agency detection module? Second, what is the evidence that points to a heritable biological factor in the creation of social attitudes such as theism and atheism?

\footnotetext{
${ }^{6}$ Numbers of other students of religion who subscribe to the modular theory of mind agree with Barrett regarding the postulation and significance of agency detection. Anthropologist Scott Atran $(2002,71)$, for instance, maintains that ' [i]n all cultures supernatural agents are conjured up because natural selection has trip-wired cognitive schema for agency detection in the face of uncertainty'. And Boyer $(2001,145)$ claims that the naturalness of belief in gods as agents 'results from the fact that our agency-detection systems are biased toward overdetection'.
} 


\section{Genetic Mechanism}

Variations in the activation threshold or sensitivity of the agency detection module could stem from a genetic mechanism. Our emphasis on the word 'could' is intended to reflect the lack of empirical evidence linking the genetic mechanisms we posit as possibilities to behavior that can be attributed to the module. This lack is related in part to the fact that research in molecular genetics thus far accomplished has focused primarily on issues of interest to the medical and biological sciences rather than the social sciences. Enough is now known, however, to allow us to point to two genetic mechanisms that result in biological phenomena that may promote variation in the sensitivity of the agency detection module. We refer, respectively, to 'polygenic inheritance' and 'polymorphism'.

Polygenic inheritance is involved in traits resulting from the influence of small, cumulative effects that are contributed by a large number of genes. Evolutionary theorists (e.g., Buss 1999; Symons 1995; Tooby \& Cosmides 1990; 1992) point out that an adaptation (i.e., a trait whose genetic basis became established in some population because it enhanced the inclusive fitness of its bearers) is often polygenically-specified, requiring complex gene expression networks to regulate its development. Such traits constitute 'complex adaptations'. Because complex adaptations owe their existence to the coordinated gene expressions of many hundreds of genes, the members of a species must be very nearly uniform in bearing the genes that underlie them, for otherwise such adaptations would not reliably survive intergenerational transmission via sexual reproduction. ${ }^{7}$

As Symons $(1995,84)$ puts it, 'for a complex adaptation to exist, all the genes [...] required to construct it must be present in all the individuals of the species. Hence, all of a species' complex adaptations must be of essentially uniform design.' This requirement imposes constraints on the amount of genetic variation that can be tolerated without compromising the functioning of the adaptation. In effect, these constraints preclude genetic variation that results in qualitative changes in the architecture of the adaptation. Within limits, however, quantitative variation can and does occur. The human stomach, for example, is a special purpose organ and it constitutes a complex adaptation whose basic design does not vary across human populations - yet

\footnotetext{
${ }^{7}$ In sexual reproduction, random halves of each parent's genes are recombined in the offspring's genome. If the complex adaptations of the parents differed in any substantive way, the random recombination of the genes for those adaptations would render it exceedingly unlikely that offspring would receive all the genes necessary for developing any of the parents' complex adaptations. As Tooby and Cosmides (1992, 78-79) put it, 'it is improbable that all of the genes necessary for a complex adaptation would be together in the same individual if the genes coding for the complex adaptation varied substantially between individuals'. For a refinement of this understanding, see Wilson $(1994,227)$.
} 
genetic variation is known to produce quantitative differences in stomach size from person to person without affecting functionality.

The example cited above is that of a physiological organ. But some structures of the mind (variously termed 'mental organs', 'mental modules', or 'psychological mechanisms') are also complex adaptations to which the constraints described above apply with equal force. In light of that understanding, Tooby and Cosmides $(1990,24)$ remark that genetic variation is 'generally limited to quantitative variation in the components of highly articulated, species-typical psychological mechanisms'. They go on to note - and their point is decidedly relevant to the argument that we are constructing about atheism - that relatively small variation in a component, such as the activation threshold of a universal psychological mechanism, can sometimes produce a dramatic effect on behavior, even to the extent of creating the spurious impression that some individuals lack what is actually a panhuman mechanism.

The agency detection 'device' (or, as we prefer to say, module) described by Barrett fits the situation sketched above. It is a complex adaptation. ${ }^{8}$ And its development and expression would seem to be subject to the polygenic processes and constraints noted. Because that it is so, it is reasonable to suppose that some degree of genetic variation could cause the module's activation threshold to vary quantitatively from person to person. That is critically relevant to our interests in theism and atheism since variation in threshold could determine whether the module would or would not initiate the process that we call 'the apotheosis of agency', producing, respectively, a bias toward theism or atheism. But rather than rest content with the plausibility of such an explanation, we must also take account of the fact that the possible outcomes suggested for polygenic effects might also be produced by the effects of polymorphism - to which we now turn our attention.

Polymorphisms are involved in the development of traits resulting from the influence of alleles (i.e., a pair or series of alternative forms of a gene occupying the same locus on homologous chromosomes). We maintain that it is reasonable to suppose that the link between the effects of polymorphism and the agency detection module is anxiety. For, on the one hand, as we show below, there is evidence that a polymorphism in a specific gene is associated with anxiety, and, on the other hand, it is clear that anxiety plays a role in the functioning of the agency detection module. That role is illustrated by

\footnotetext{
${ }^{8}$ Barrett $(2000 ; 2004)$ holds that the 'hypersensitive agency detection device' is an evolutionary legacy from our hunter-gatherer ancestors whose survival depended on the detection of agency, either when searching for prey or when it seemed likely that they 'might be prey for someone or something else' $(2004,39)$. Boyer $(2001,145)$, Atran $(2002,78)$, and numbers of others (including the authors of the present paper), concur.
} 
Barrett's discussion of how changes in the module's sensitivity relate to what he characterizes as 'personal and immediate contexts' $(2004,39)$.

In considering such contexts, Barrett directs our attention to two phenomena. First, an individual's memory of a past anxiety-evoking event increases the agency detection module's sensitivity to particular environmental features that evoke a similar anxiety (e.g., an individual once bitten by a snake becomes more likely to mistake a garden hose lying in the grass for a snake). Second, the module's sensitivity temporarily intensifies when an individual experiences anxiety because of the perception that the immediate situation is one in which urgent action related to self-survival may be required. The first phenomenon is a conditioned fear response, and in both phenomena concern with harm avoidance automatically evokes agency-related anxiety followed by a heightening of the module's sensitivity.

These phenomena point to the likelihood that functional connectivity exists between the neural circuits that create anxiety related to harm avoidance and the circuits that regulate the sensitivity of the agency detection module. The existence of such connectivity would imply that the module's sensitivity varies across individuals in the population depending on their innate susceptibility to anxiety, as displayed by anxiety-related behaviors. It has long been known that individuals differ regarding this susceptibility, but why this is so has only been elucidated at the level of molecular genetics during the last decade. The findings that led to that result are described below, and for those of our readers who are unfamiliar with molecular genetics, we provide an overview of certain relevant concepts and terminology. ${ }^{9}$

By the 1990s it was well known that a protein, 5-hydroxytryptamine or 5-HT, otherwise known as serotonin, mediates neurotransmission and influences cognition and moods such as anxiety, and that another protein, the serotonin transporter or 5-HTT, is involved in fine-tuning serotonergic neurotransmission (Westenberg 1996). It was also known that the serotonin transporter is encoded by a single transporter gene, designated SLC6A4, on chromosome 17 (Lesch et al. 1994).

\footnotetext{
${ }^{9}$ Overview of relevant genetic terminology. A chromosome is a threadlike form of DNA, a molecule with chemical bases attached in pairs along its centerline. The lengths of DNA segments are thus expressed in units of base pairs (bp). A gene is a segment of chromosomal DNA, typically about $3000 \mathrm{bp}$ long, which is encoded (via the ordering of its bases) with instructions for making its own distinctive protein. Near one end of each gene is a short segment of DNA called a 'promoter'. When a chemical trigger activates the promoter it initiates a process called 'transcription' - in which the gene's code is copied onto ribonucleic acid (RNA). The RNA then participates with other intracellular materials to make the protein. The proteins thus produced serve various purposes essential to life and, of special relevance here, some genes produce proteins which regulate the expression of other genes. For example, a 'transporter gene' produces a 'transporter' - a protein whose function is to ensure that another gene's protein is present at the right place in the right amount.
} 
In 1996 researchers discovered a polymorphism in the promoter region of the serotonin transporter gene (SLC6A4), involving a pair of alleles (Heils et al. 1996). In the promoter region of one of these alleles there is a deletion of 44 base pairs, making it a short form of the gene relative to the long form in which the 44 base pairs are retained. In the decade that followed a number of studies concerning this polymorphism were conducted (e.g., Lesch et al. 1996; Hariri et al. 2002; Caspi et al. 2003; Pezawas et al. 2005). The following is a brief description of the results of this research.

It was found that the deletion of 44 base pairs in the promoter region of the serotonin transporter gene alters the promoter's performance and reduces the efficiency of transcription so that less of the serotonin transporter is produced. This transporter is a membrane protein and one of its functions is to reabsorb excess synaptic serotonin; thus, less transporter results in more synaptic serotonin. Hence, the brains of individuals bearing the short allele are exposed to more serotonin than are the brains of bearers of the long allele during fetal development. Particularly affected are the amygdala and the perigenual cingulate. The amygdala initiates fear responses and the cingulate dampens the output of the amygdala. Functional connectivity exists between the amygdala and the cingulate, and Pezawas et al. (2005, 831) aver that connections of this sort 'represent a functional feedback circuitry that regulates amygdala processing'. The impact of intense serotonin activity on the developing brain of a bearer of the short allele degrades the functional connectivity on which cingulate regulation of the amygdala depends. In light of the above, Pezawas et al. $(2005,828)$ conclude that these early changes in connectivity 'cause permanent elevations in anxiety-related behaviors in adulthood'.

Compared to bearers of the long allele, for example, individuals carrying the short allele are more likely to acquire conditioned fear responses (Hariri et al. 2002, 401). And, unlike bearers of the long allele, carriers of the short allele experience high levels of anxiety related to harm avoidance on a daily basis (Lesch 1996; Pezawas et al. 2005). It is noteworthy that these are the types of anxiety-related behaviors that Barrett associates with heightened sensitivity of the agency detection module.

In sum, carriers of the short allele manifest anxiety-prone temperaments according to well-validated measures such as the Harm Avoidance Subscale of the Tridimensional Personality Questionnaire (Cloninger et al. 1993). In contrast, those who bear the long allele have relatively anxiety-free temperaments and they experience anxiety related to harm avoidance less frequently than those carrying the short allele. This finding implies that short allele 
individuals are responding to anxiogenic cues from the environment that are not perceived by those carrying the long allele - which is consonant with a functional connectivity between neural circuits involved in creating anxiety and those regulating the sensitivity of the agency detection module. We suggest that since about 43 per cent of the population samples measured thus far bear the short allele and 57 per cent the long allele, this polymorphism could be a significant source of variation in the module's sensitivity across individuals in the general population. ${ }^{10}$

The biological consequences of the polygenic and polymorphic mechanisms that we describe could, either separately or in concert or in combination with some mechanism(s) as yet undiscovered, introduce a heritable biological factor into theories about theism and atheism. Apropos of undiscovered mechanisms, a study by Borg et al. (2003) indicates that the serotonin system may provide a biological basis for 'spiritual' experiences. Borg et al. speculate that variability in serotonin receptor density may explain why individuals vary in spiritual zeal, although the genetic mechanism underlying variability in receptor density, they are careful to point out, 'remains to be confirmed in humans' $(2003,1968)$. Elucidation of the pertinent genetic mechanism may soon be forthcoming in consequence of recent dramatic increases in the knowledge and technical tools available to molecular geneticists (e.g., see Benjamin et al. 2002).

We hasten to add that the genetic mechanisms that we foreground above are not determinative - there is no such thing as 'the god gene', which is the unfortunate (and disavowed) title of an otherwise informative book (Hamer 2004). Rather, the biological effects of these genetic mechanisms subtly influence the extent to which individuals respond to aspects of the environment that are conducive to theism and those that are conducive to atheism. Thus, our suggested insertion of a heritable biological factor into Barrett's explanatory schema does not imply a downgrading of environmental influence. It does imply, however, that the variance in vulnerability to theism or to atheism across individuals in a population will have both environmental and genetic components.

As we previously pointed out, research in the field of molecular genetics that would identify the genetic mechanism that does (rather than could) insert our proposed heritable biological factor into explanations of theism and atheism has yet to be accomplished. Even though a specific genetic mechanism is not yet established, however, the field of behavior genetics

\footnotetext{
${ }^{10}$ Such instances of 'balanced polymorphism' are not abnormal or uncommon in humans and other organisms (e.g., as in the human A, B, O blood groups). The function of many polymorphisms is unclear, but a persuasive suggestion is that they may protect against pathogens (Tooby \& Cosmides 1990, 32).
} 
provides evidence suggesting that some such mechanism exists - as next described.

\section{Evidence of a Heritable Biological Factor}

To clarify the relationship between our hypothesized biological factor and the kind of evidence provided by empirical studies in behavior genetics, it is useful to summarize some of the consequences of our proposed modification of Barrett's approach.

In describing the consequences that would ensue from our hypothesized factor, we assume, for illustrative purposes, that it actually exists. We assume, moreover, that it exists as a variation in the sensitivity of the agency detection module. We further assume that such variation is traceable to one of the two posited genetic mechanisms discussed earlier for which we can presently make the most plausible illustrative case: polygenic inheritance.

Quantitative differences in a component of a polygenically-specified adaptation (in this case, the agency detection module's sensitivity) will vary continuously across a population. There will thus be a continuum from low to high values of sensitivity, and the number of individuals at each point on the continuum will generally correspond to a normal (i.e., Gaussian) distribution (Stebbins 1977, 44). Graphically, this is a bell-shaped curve with a single mode and two tails that include, respectively, the lowest and highest values. Most individuals will be clustered around the mean or average value, and relatively few will be in the tails.

Since the environmental influences experienced by any given individual may override genetic influences and vice versa, there will be theists and atheists at every point of the continuum, including the tails. But individuals in the tails will be relatively resistant to the environment. Hence, those with very low sensitivity will tend to be atheists even in theistic environments, and those with very high sensitivity will tend to be theists even in atheistic environments. For the multitude between the extremes of the continuum, the environment will be much more determinative of a theistic or atheistic orientation.

Barrett $(2004,122)$, it may be recalled, claims that while atheism requires special - and uncommon - conditions to prosper, conditions that 'must be deliberately produced by human activity', theism, in contrast, 'finds almost all human environments fertile'. We accept that claim, and when we apply it to the world's population, we conclude that most of the individuals clustered around the mean will be exposed to environments 'fertile' for theism, and they will tend to become theists regardless of which side of the mean 
they are on. We further conclude that the insertion of our biological factor into Barrett's schema is consonant with his claim that atheism necessarily represents a minority position. ${ }^{11}$

It is also consonant with Barrett's $(2004,13)$ claim that non-reflective beliefs shape reflective beliefs and 'make reflective beliefs more plausible'. Individuals at the high sensitivity end of the continuum, who respond to theistic environmental influences by forming or accepting a reflective belief in god, will experience support for that belief from a substrate of non-reflective beliefs about supernatural agents. This substrate will exist because it is richly furnished with amorphous agent-like outputs from their agency detection modules. Because of the high sensitivity of their modules, such outputs are triggered by ambiguous inputs. Individuals at the low end of the sensitivity continuum may also respond to theistic influences by forming or accepting reflective beliefs in god. They, however, will experience comparatively little or no support for those beliefs from a substrate of non-reflective beliefs about supernatural agents because their relatively insensitive agency detection modules are rarely triggered by ambiguous inputs.

This line of reasoning suggests that, depending on their module's sensitivity, individuals who espouse theism will exhibit a range in the strength of conviction regarding their belief in god. This, in turn, implies the existence of another continuum, one derived from the sensitivity continuum and that represents a trait that may be called 'intensity of theistic conviction'. It will vary from low to high in parallel with the sensitivity continuum and, like that continuum, it will correspond to a normal distribution. The existence of such a continuous latent trait would affect many attitudes and beliefs, especially those involving (1) depth of theistic belief, (2) its importance in an individual's life, and (3) presumption that moral precepts are divinely inspired.

If the individual espouses one of the culturally available religions, these three attitudes and beliefs would influence the individual's responses on widely-used scales that measure various dimensions of religiosity. The dimensions well established in the literature that come closest to reflecting the attitudes and beliefs listed above are, respectively, Intrinsic Religiousness (Allport Intrinsic-Extrinsic Scale), Religious Salience (Allport-VernonLindsey Religious Value Scale), and belief in Divine Law (Wilson-Patterson Conservatism Scale). Measurements of these specific dimensions have frequently appeared in published reports by researchers (mainly sociologists

\footnotetext{
${ }^{11}$ Typically, recent surveys which indicate the fraction of atheists in the world's population have resulted in values ranging from 2.4 per cent to 4 per cent, but Zuckerman (2006) suggests that the value may be higher (i.e., between 8 per cent and 12 per cent). If so, atheism is still the position of a very small minority.
} 
of religion and psychologists of religion) who usually deem them to be learned predispositions resulting solely from environmental sources. They typically do not raise the possibility that these dimensions may have a heritable biological component as well as an environmental one. Behavior geneticists, however, have explored this possibility.

The overarching goal of behavior genetics is to understand genetic influences on the behavior of humans and other living organisms. This cannot be accomplished without taking into account complementary environmental influences. Various methodologies are used to untangle genetic and environmental influences with regard to a given behavior or trait, but the empirical research relevant to understanding theism and atheism is largely based on a single methodology: that of twin studies.

Identical or monozygotic twins share 100 per cent of their genes, whereas fraternal or dizygotic twins have only half their genes in common. Trait measurements on pairs of identical twins raised together and raised apart, and on fraternal twins raised together and apart, constitute 'natural experiments' that yield separate estimates of the influence of genes and the environment. Basic data are generated largely by administering questionnaires to often sizeable populations and/or by more intensive interviewing about attitudes and life history events.

The methodology of twin studies divides the sources of influence on traits into three quantifiable, related components: heritability (which is indicative of genetic influence), shared environment, and unshared environment. Although we cannot attempt an adequate explication of technical matters here, we think it prudent to note in passing that heritability in this case is a population statistic that can vary depending on the given population. The derived values of the components analyzed, moreover, are estimates that approximate actual values in the population. Technically understood, these are estimates of the ability of components to account for variance in the given traits, not for the traits themselves. It is beyond the scope of this paper to delve further into the rationale of twin studies. ${ }^{12}$ It is, however, pertinent to define certain terms used in reporting the results of such studies.

Heritable. The words 'heritable' and 'heritability' have been adopted by geneticists and given more restricted and precise meanings. Geneticists regard as heritable those traits stemming from genetic differences among individuals in a population. Traits possessed by all humans because those traits express a species-wide genetic endowment, however, are not dubbed heritable. For example, 'eye color' and 'having two eyes', taken as traits, both

\footnotetext{
${ }^{12}$ The methodology of twin studies, criticisms of its assumptions, and rebuttals by its proponents are amply covered in the literature (e.g., Bouchard \& Segal 1993, Plomin et al. 2001).
} 
involve genetic material passed from parents to offspring, but the former is called heritable and the latter is not.

Heritability. The word 'variance' refers to a way of specifying precisely in numerical form how widely individuals in a population vary in regard to some trait. Heritability in the broad sense is the ratio of genotypic and phenotypic variances. It is an index of the relative significance of genetic differences as a cause of individual differences in a population. As an index, it is conventionally conceptualized as varying from zero to one or, alternatively, from zero per cent to a hundred per cent. Given the limitations of twin study methodology acknowledged in the literature (see Bouchard \& Segal 1993 and Plomin et al. 2001), the question of how to interpret the estimated values of heritability arises. Broadly stated, our interests lie in knowing if genetic influences are non-negligible and should be included in explanations involving a given trait. Based on statements by knowledgeable commentators who have published reviews of the twin study results soon to be cited in this paper (see below), it appears supportable to conclude that estimates of heritability equal to or near zero per cent indicate no (or negligible) genetic influence, whereas values greater than about twenty per cent indicate that it is highly probable that genetic influence is non-negligible.

Environmentality. Each individual has an idiosyncratic environmental history which begins at conception. Environmentality includes everything not encoded in the genes, and ranges from the chemical influences of the womb and familial influences during childhood to many diverse influences experienced as an adult. The methodology of twin studies provides estimates of environmental influence in two categories: the 'shared environment' (typically familial), which consists of all the external influences that tend to make traits similar among individuals (typically siblings); and the 'unshared environment', which consists of all the external influences that tend to make traits dissimilar.

The foregoing definitions provide the basis for understanding the findings of twin studies, but the scales administered to the twins also require comment. In adapting the twin study methodology for analyzing religious dimensions, behavior geneticists made use of available scales developed for measuring those dimensions. Some of those scales have been used for decades by students of religion, and their advantages and disadvantages have been critically discussed in the literature. Whatever their shortcomings may be, however, they suffice for our purposes because it is plausible to assume that the responses evoked from respondents by the scales measuring the selected dimensions would be affected by our hypothesized biological 
factor - thus making that factor a possible source of the genetic component of the given trait. ${ }^{13}$ The evidence that such a component exists for three dimensions that we have selected is as follows:

Intrinsic Religiousness. Bouchard et al. (1999) measured this religious dimension in a sample of adult twins. Heritability was 39 per cent, environmentality 61 per cent (this includes shared and unshared influences).

Religious Salience. Carver \& Udry (1997) measured this dimension in a sample of adolescent twins. Heritability was 29 per cent, shared environment 42 per cent, unshared environment 29 per cent.

Divine Law. Martin et al. (1986) studied large samples of adult twins from Australia and England, measuring four religious dimensions including belief in Divine Law. Heritability for this dimension was 42 per cent, shared environment 26 per cent, unshared environment 52 per cent. The average of heritability for the four dimensions was 29 per cent, that of shared environment 24 per cent, and that of unshared environment 47 per cent.

The above data are only a small selection from two dozen or so religious dimensions that have been studied by behavior geneticists from the mid1980s to the present (see D'Onofrio et al. 1999 and Bouchard \& McGue 2003 for reviews of that research). Several significant points have emerged from such research, some of which are apparent even from the limited data we have cited. First, D'Onofrio et al. $(1999,969)$ conclude from their review that the findings of these studies make it evident that 'sociological and behavior research on the transmission or inheritance of religious beliefs and practices can no longer ignore genetic influences'. Second, although much past research by students of religion has focused on the relative importance of early familial influences on dimensions of religiosity, twin studies suggest that for many dimensions genetic influences are as important as influences of the familial shared environment, and both are considerably overshadowed by the influences of unshared environment.

It is noteworthy that genes do not influence all religious dimensions. Take, for instance, Religious Affiliation and Church Attendance, dimensions that have been analyzed by behavior geneticists by means of twin studies. Eaves et al. (1990) report that heritability for Religious Affiliation (e.g., Christian, Jewish, Muslim) is zero per cent and environmentality is a hundred per cent. Truett et al. (1992) report that for males the heritability for Church

\footnotetext{
${ }^{13}$ These scales generally present the subject with a statement and five graduated responses ranging from 'strongly agree' to 'strongly disagree'. For example, on the Intrinsic Religiousness Scale a typical statement is: 'Quite often I have been keenly aware of the presence of God or the Divine Being.' It is clearly plausible that individuals at the high end of our posited sensitivity scale, who possess a substrate of non-reflective beliefs about supernatural agents, would tend to agree strongly, whereas individuals at the low end would tend to disagree.
} 
Attendance is zero per cent and environmentality a hundred per cent, but for females heritability is 21 per cent and environmentality 79 per cent. It appears that, on the one hand, it would display a better grasp of reality if the latter data were to be considered in explanations of the widely-observed fact that the large majority of church attendees are female and, on the other hand, it seems that sociological explanations of Church Affiliation would be improved by the inclusion of the former data indicating that it results solely from sociological and environmental influence.

\section{Conclusion}

The reader will have noted that we touch on a wide diversity of topics in this paper. The heterogeneity encountered, however, is in the service of three advocacies.

First, we recommend that efforts to explain theism and atheism should probe for the possible significance of biological factors. The studies in behavior genetics that we cite indicate that not all expressions of what we conceive of as religiosity involve non-negligible biological factors. For some, environmental explanations suffice. But for others, biological mechanisms need to be taken into account if we are to widen and deepen our efforts at explanation. In that regard, and lest there be any misunderstanding, we explicitly re-emphasize here a crucial understanding that pervades this paper: no one inherits attitudes and beliefs. What one inherits are biological structures. Those structures can be important for the formation and harboring of attitudes and beliefs through causal chains, some of which are now more or less understood.

One of the examples that we cite has to do with a polymorphism that is connected to differential expressions of anxiety in adult life and that may well - along with other factors - differentially affect the triggering of Barrett's 'hypersensitive agency detection device'. Another plausible hypothesized candidate is polygenic inheritance, which admits of quantitative inter-individual differences in the sensitivities and intensities of complex psychological adaptations. Plausible theorizing, supported by the evidence of behavior genetics, leads us to conclude that biological factors, in interaction with environmental factors, often affect the sensitivities and insensitivities of individuals to various features of their behaviorally relevant environments. An understanding of such disposing factors can help us account for obvious differences displayed by individuals vis-à-vis their ambient worlds.

Second, we recommend taking Barrett's explanations of atheism and theism as starting places, and extending them by introducing a hypoth- 
esized biological factor. We argue that it is reasonable to suppose that our hypothesized factor - quantitative variance in sensitivity of the agency detection module - is a possible and credible candidate for inclusion. What is especially noteworthy about our hypothesized factor is that it is derived from, and modifies, Barrett's schema for explaining theism and atheism. By so enhancing Barrett's view, we hold that we can explain more about theism and atheism than he does.

A hallmark of a good theory is the appreciable extent to which it accounts for what is known about the phenomena it purports to explain. In our judgment, theories that closely conform to the Standard Social Science Model as described and criticized by Tooby and Cosmides (1992) tend to be limited in what they can explain. Their apparent celebration of cultural diversity and cultural programming, indeed, often masks narrow and inadequately examined culture-bound categories and understandings. We think that Bainbridge's explanation of atheism suffers from that liability, for it depends on Western understandings of supernaturalism, anxieties respecting death, and intra-familial obligations, understandings that may not apply in all cultures. In contrast, the cognitive paradigm espoused by Barrett is grounded in our knowledge of panhuman adaptations, including what people in diverse disciplines claim to know about the evolved architecture of the human mind-brain. We deem Barrett's theorizing to be more comprehensive concerning atheism and theism than Bainbridge's. But it, too, is limited, especially in that it opts for an environmental explanation of atheism. Further, and despite its attractions, Barrett's approach to both theism and atheism cannot account for the remarkable data and conclusions that behavior geneticists furnish us based on twin studies.

Third, we advocate our approach as a plausible link between what is valuable and exciting in the cognitive science approach espoused by Barrett and the valuable and exciting work of behavior geneticists. Further, our approach introduces into the explorations of religion some consiliance with the brilliant discoveries and theorizing of molecular geneticists.

As we have pointed out in several places, the studies in behavior genetics that we cite indicate the significance of biological variables in some (but not all) explanations of expressions of religiosity. The biological evidence, moreover, testifies to the importance of sociological analyses. That is, in the studies cited, whenever heritability and environmentality are both present in non-negligible degrees, and therefore partnered in explanation, environmentality is characteristically the senior partner. Armed with that understanding, we conclude with this prediction: that the social sciences 
will improve their persuasiveness and their importance by breaking out of their isolation and joining with the other sciences, particularly the biological sciences, in complementary and mutually clarifying explorations of the human condition.

Bibliography

Alford, John R. \& Carolyn L. Funk \& John R. Hibbing

2005 Are Political Orientations Genetically Transmitted? - American Political Science Review 99(2), 153-167.

Atran, Scott

2002 In Gods We Trust: The Evolutionary Landscape of Religion. Oxford: Oxford University Press.

\section{Baggini, Julian}

2003 Atheism: A Very Short Introduction. Oxford: Oxford University Press.

\section{Bainbridge, William S.}

1995 Neural Network Models of Religious Belief. - Sociological Perspectives 38, 483-495.

2005 Atheism. - Interdisciplinary Journal of Research on Religion 1(1), 1-24. [http://www.bepress.com/ijrr]

\section{Bainbridge, William S. \& Rodney Stark}

1979 Cult Formation: Three Compatible Models. - Sociological Analysis 40, 283-295.

\section{Barrett, Justin L.}

2000 Exploring the Natural Foundations of Religion. - Trends in Cognitive Sciences 4, 29-34.

2004 Why Would Anyone Believe in God? Walnut Creek, CA: Altamira Press.

\section{Benjamin, Jonathan \& Richard Epstein \& Robert Belmaker}

2002 Molecular Genetics and the Human Personality. Washington: American Psychiatric Publishing, Inc.

Borg, Jacqueline \& Bengt Andrèe \& Henrik Soderstrom \& Lars Farde 2003 The Serotonin System and Spiritual Experiences. - American Journal of Psychiatry 160, 1965-1969. 
Bouchard, T. J., Jr. \& N. L. Segal

1993 Twins as a Tool of Behavior Genetics. Chichester: Wiley.

Bouchard, T. J., Jr. \& M. McGue \& D. Lykken \& A. Telegren

1999 Intrinsic and Extrinsic Religiousness: Genetic and Environmental Influences. - Twin Research 2, 88-99.

Bouchard, T. J., Jr. \& Matt McGue

2003 Genetic and Environmental Influences on Human Psychological Differences. - Journal of Neurobiology 54(1), 4-45.

Boyer, Pascal

1994 The Naturalness of Religious Ideas: A Cognitive Theory of Religion. Berkeley: The University of California Press.

2001 Religion Explained: The Evolutionary Origins of Religious Development. New York: Basic Books.

2004 Out of Africa: Lessons from a Byproduct of Evolution. - Timothy Light \& Bryan C. Wilson (eds), Religion as Human Capacity: A Festschrift in Honor of E. Thomas Lawson, 27-43. Leiden and Boston: E. J. Brill.

\section{Buller, David}

2005 Adapting Minds. Cambridge, MA: Massachusetts Institute of Technology Press.

Buss, David M.

1999 Evolutionary Psychology: The New Science of the Mind. Boston: Allyn \& Bacon.

\section{Carver, K. \& J. Udry}

1997 Differences in the Heritability of Religious Attitudes Across Levels of Parental Control. Paper presented at the Annual Meeting of the American Sociological Association, Ontario.

Caspi, A. \& J. McClay \& T. Moffit \& J. Mill \& J. Martin \& I. Craig \& A. Taylor \& R. Poulton

2003 Role of Genotype in the Cycle of Violence in Maltreated Children. - Science 297, 851-853.

\section{Cloninger, C. R. \& D. Svrakic \& T. Przybeck}

1993 A Psychological Model of Temperament and Character. - Archives of General Psychiatry 50, 975-990.

D'Onofrio, B. M. \& B. L. Eaves \& L. Murrell \& H. Maes \& B. Spilka

1999 Understanding Biological and Social Influences on Religious Affiliation, Attitudes, and Behaviors: A Behavior Genetic Perspective. - Journal of Personality 67(6), 954-984.

Eaves, L. J. \& N. G. Martin \& A.C. Heath

1990 Religious Affiliation in Twins and Their Parents. - Behavior Genetics 20, 1-22. 


\section{Gallup, George C. \& Michael Lindsay}

1999 Surveying the Religious Landscape. - Archives of General Psychiatry $38,1322-1329$.

Guthrie, Stewart E.

1993 Faces in the Clouds: A New Theory of Religion. Oxford: Oxford University Press.

\section{Hamer, Dean}

2004 The God Gene: How Faith is Hardwired into Our Genes. New York: Doubleday.

Hariri, A. \& V. Mattay \& A. Tessitore \& B. Kolachana \& F. Fera \& D. Goldman \& M. Egan \& D. Weinberger

2002 Serotonin Transporter Genetic Variation and the Response of the Human Amygdala. - Science 297, 400-404.

Hayes, Bernadette C.

2000 Religious Independents Within Western Industrial Nations: A SocioDemographic Profile. - Sociology of Religion 61, 191-207.

Heils, A. \& A. Teufel \& S. Petri \& G. Stoeber \& P. Riederer \& D. Bengal \& K. P. Lesch

1996 Allelic Variation of Human Transporter Gene Expression. - Journal of Neurochemistry 66(6), 2621-2624.

Jagodzinski, Wolfgang \& Andrew Greely

n.d. The Demand for Religion: Hard Core Atheism and 'Supply Side' Theory. [http://www.agreeley.com/articles/hardcore.html]

James, William

1929 (1902) The Varieties of Religious Experience: A Study in Human Nature. New York: The Modern Library.

Larson, Edward \& Larry Witham

1997 Letter. - Nature 386, 435-436.

1998 Letter. - Nature 394, 313.

Lesch, K. P. \& U. Balling \& J. Gross \& K. Strauss \& B. Wolozin \& D. Murphy \& P. Rieder

1994 Organization of Human Transporter Gene. - Journal of Neurological Transmission 95, 157-164.

Lesch, K. P. \& D. Bengal \& A. Heils \& S. Sabol \& B. Greenberg \& S. Petri \& J. Benjamin \& C. Mueller \& D. Hamer \& D. Murphy

1996 Association of Anxiety-Related Traits with a Polymorphism in the Serotonin Transporter Gene Regulatory Region. - Science 274, 1527-1531. 
Leuba, J. H.

1916 The Belief in God and Immortality. Boston: Sherman French \& Co.

Martin, N. G. \& L. Eaves \& A. Heath \& R. Jardin \& L. Feingold \& H. Eysenk

1986 Transmission of Social Attitudes. - Proceedings of the National Academy of Sciences 83, 4364-4368.

Pezawas, L. \& A. Meyer-Lindenberg \& E. Drabant \& B. Verchinski \& K. Munoz \& B. Kolachana \& M. Egan \& V. Mattay \& A. Hariri \& D. Weinberger

2005 5-HTTLPR Polymorphism Impacts Human Cingulate-Amygdala Interactions. - Neuroscience 8, 828-834.

Plomin, R. \& J. DeFries \& G. McClearn \& P. McGuffin

2001 Behavioral Genetics. New York: Worth.

Pyysiäinen, Ilkka

2003 True Fiction: Philosophy and Psychology of Religious Belief. - Philosophical Psychology 16 (1), 109-125.

2004 Intuitive and Explicit in Religious Thought. - Journal of Cognition and Culture 4(1), 123-150.

Saler, Benson

2000 (1993) Conceptualizing Religion: Immanent Anthropologists, Transcendent Natives, and Unbounded Categories. New York and Oxford: Berghahn Books.

Saler, Benson \& Charles A. Ziegler

2005 Dracula and Carmilla: Monsters and the Mind. - Philosophy and Literature 21(1), 218-227.

\section{Sperber, Dan}

1997 Intuitive and Reflective Beliefs. - Mind and Language 12, 67-83.

\section{Stark, Rodney \& William S. Bainbridge}

1979 Of Churches, Sects, and Cults: Preliminary Concepts for a Theory of Religious Movements. - Journal for the Scientific Study of Religion 18, 117-131.

1980 Towards a Theory of Religion: Religious Commitment. - Journal for the Scientific Study of Religion 19, 114-128.

1985 The Future of Religion. Berkeley: The University of California Press.

1987 A Theory of Religion. New York: Lang \& Toronto Studies in Religion.

Stebbins, G. L.

1977 Processes of Organic Evolution. Englewood Cliffs: Prentice-Hall. 


\section{Symons, Donald}

1995 On the Use and Misuse of Darwinism in the Study of Human Behavior. - Jerome H. Barkow \& Leda Cosmides \& John Tooby (eds), The Adapted Mind: Evolutionary Psychology and the Generation of Culture, 137-162. New York: Oxford University Press.

\section{Tooby, John \& Leda Cosmides}

1990 On the Universality of Human Nature and the Uniqueness of the Individual: The Role of Genetics and Adaptation. - Journal of Personality 58(1), 17-67.

1992 The Psychological Foundations of Culture. - Jerome H. Barkow \& Leda Cosmides \& John Tooby (eds), The Adapted Mind: Evolutionary Psychology and the Generation of Culture, 19-136. New York: Oxford University Press.

Truett, K. \& L. Eaves \& A. Heath \& J. Meyer \& N. Martin

1992 Religion and Education as Indicators of Attitudes: A Multivariate Analysis. - Behavior Genetics 22, 43-62.

Westenberg, H. G. \& D. L. Murphy \& J. A. Den Boer

1996 Advances in the Neurobiology of Anxiety Disorders. New York: Wiley.

\section{Wilamowitz-Möllendorff, Ulrich von}

1956 (1931) Der Glaube der Hellenen, Vol. 1. Basle: Benno Schwabe \& Co.

\section{Wilson, David Sloan}

1994 Adaptive Genetic Variation and Human Evolutionary Psychology. - Ethnology and Sociobiology 15, 219-235.

2002 Darwin's Cathedral: Evolution, Religion, and the Nature of Society. Chicago: University of Chicago Press.

\section{Zuckerman, Phil}

2006 Atheism: Contemporary Rates and Patterns. - Michael Martin (ed.), The Cambridge Companion to Atheism. Cambridge: Cambridge University Press. 
